\title{
Teorik Nihai Kazık Taşıma Gücü Hesaplamaları ile Kazık Yükleme Yöntemlerin Karşılaştırmalı Analizi
}

\author{
${ }^{1}$ Halil Kabaca, *2ं̇̀sa Vural \\ ${ }^{1}$ Fen Bilimleri Enstitüsü, İnşaat Mühendisliği EABD, Sakarya Üniversitesi, Türkiye \\ *2Teknoloji Fakültesi, İnşaat Mühendisliği Bölümü, Sakarya Uygulamalı Bilimler Üniversitesi, Türkiye
}

\section{ÖZET}

Kendisi için elverişsiz veya yetersiz bir zemine oturan mühendislik yapısının, oturduğu zemini daha verimli kullanma yollarından birisi zemin içerisinde kazık imalatı yapmaktır. Büyük ölçekli yapılarda kazık taşıma gücünü hatalı belirlemek aşırı dizayna veya güvensiz tarafta kalmaya neden olabilmektedir. $\mathrm{Bu}$ nedenle kazıkların zemin ve/veya kaya ortam içerisindeki taşıma gücünü gerçeğe yakın bir biçimde belirlemek gerek yapı güvenliği gerekse ekonomi açısından önem taşımaktadır.Bu çalışmada, SPT deneyinden kazık nihai taşıma gücü veren teorik yöntemler ile matematiksel modele dayalı kazık yükleme deneyi değerlendirme yöntemleri karşılaştırılmıştır. 8 adet kazık yükleme deneyi; SPT deneyine dayanan teorik yöntemler ve matematiksel modele dayalı kazık yükleme deneyi değerlendirme yöntemleri ile tahlil edilmiştir. Teorik SPT yöntemleri ve kazık yükleme deneyi değerlendirme yöntemleri iki ayrı blok olarak kıyaslanmıştır.

Anahtar kelimeler: Kazık yükleme deneyi, SPT ile kazık taşıma gücü, fore kazık.

\section{Comparative Analysis of Pile Bearing Capacity Calculations with Theoretical Final Pile Load Calculations}

\begin{abstract}
One of the ways to make foundation soil in engineering structure more efficient is to install piles in the soil. Incorrect determination of pile bearing capacity in large buildings can lead to over design or insecure situation. For this reason, it is important to determine the pile bearing capacity in the soil and / or rock in a realistic way, in terms of construction safety and economics.In this study, pile load test evaluation methods based on mathematical model and theoretical methods of pile bearing capacity were compared. 8 pile loading tests; have been analyzed by theoretical methods based on the SPT test and pile loading test methods based on the mathematical model. Theoretical SPT methods and pile loading test evaluation methods are compared as two separate blocks.
\end{abstract}

Key words: Pile loading test, pile bearing capacity with SPT, bored pile.

\section{Giriş}

Dünya' da artan kentleşme ile görece dar alanlara görece daha uzun ve ağır yapılar inşa edilmektedir. Buna bağlı olarak yapının oturduğu zemini daha verimli bir biçimde kullanma ihtiyacı doğmaktadır.. İnşa edilmek istenen yapının ihtiyacı olan dayanımı karşılayamayan, görece zayıf zeminlerde yapı temelinin altına kazık imal edilmesi, zemin/kaya ortamından daha verimli bir şekilde yararlanmanın yollarından birsidir.

İnsanoğlunun ağaç gövdelerinden imal edilen ahşap kazıkları kullanmaya başlaması M.Ö. 12. yy’a kadar dayanmaktadır [3].

*Corresponding author: Address: Teknoloji Fakültesi, İnşaat Mühendisliği Bölümü, Sakarya Uygulamalı Bilimler Üniversitesi, 54187, Sakarya TÜRKIYYE . E-mail address: ivural@sakarya.edu.tr, Phone: +902642956479 
Kazıklar, yapı yükünü sert/sıkı zemin veya kaya tabakasına aktaracak biçimde veya içinde bulunduğu görece zayıf olan zemini sürtünme ve uç direnci aracılığıyla daha verimli kullanabilecek biçimde tasarlanır [1].
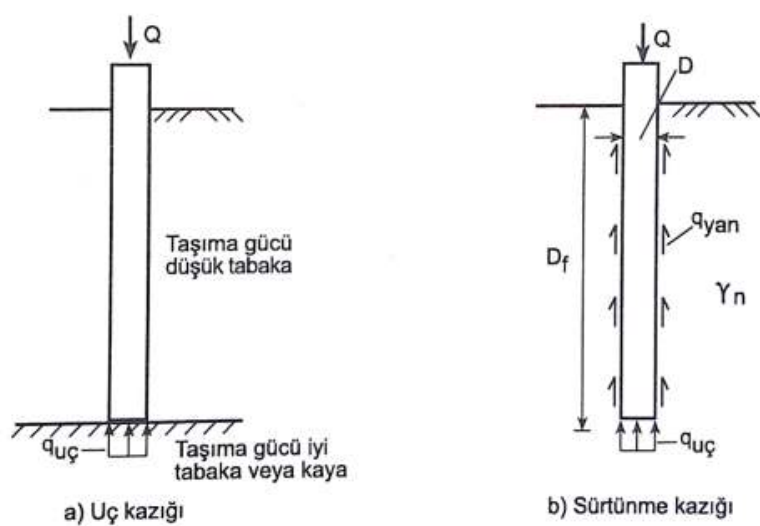

Şekil 1.1. Çalışma biçimine göre kazıklar [2]

İmal ediliş olarak temel olarak iki yöntem bulunmaktadır. Bunlardan biri çakma (driving) diğeri ise delme (fore) kazıklardır. Çakma kazıklar, zemin içerisine çakılarak teşkil edilen kazıklardır ve içerisine çakıldığı zemini yanlara itip sıkıştırması nedeniyle bu zeminin sıkılığını/sertliğini artırarak zemini görece iyileştirme gibi bir faydaları da bulunmaktadır [2].

Fore kazıklar ise kazık hacmi kadar zeminin boşaltılmasından sonra bu boşluğa kazığın teşkil edilmesi ile imal edilirler. Fore kazıklar zemini yana doğru ötelemez ve sıkıştırmazlar. Hatta bazı durumlarda içeri doğru ötelenme olup zeminin gevşemesi mümkündür [3].

Kazıklar sayesinde yapı yükleri, sadece yapının oturduğu temel zeminine değil, ilgili zeminin daha derin tabakalarına da aktarılabilir. Mekanik anlamda bu verimin ne kadar olacağı ve zemin/kaya ortamında nasıl yararlanılacağı konusunda literatürde bir çok araştırmacı, çalışmalar yapmışlardır. Kazıkların taşıma gücünü belirlemeye yönelik temel olarak iki yaklaşım vardır. Bunlardan biri kazığın çevresindeki zeminin laboratuvarda veya arazide belirlenen mekanik özelliklerine bağlı olarak kazığın taşıma gücünü belirleme, diğeri ise kazığıı kendisinin yükleme deneyine tabi tutularak taşıma gücünü belirlemektir [1].

Kazıklar, temel olarak Şekil 1.1.'de de belirtildiği gibi yanal sürtünme direnci ve uç direnci gösterirler. $\mathrm{Bu}$ dirençleri belirlemek amacıyla literatürde, kazığın imal ediliş şekline, kazığın içerisinde bulunduğu zemin/kaya cinsine ve mekanik özelliklerine, sahada yapılmış olan arazi deneylerine (SPT, CPT, vs.) bağlı olarak taşıma gücü bağıntıları geliştirilmiştir.

Genel olarak kazık düşey yük taşıma kapasitesi en basit haliyle;

$$
\mathrm{Q}_{\text {ult }}=\mathrm{Q}_{\mathrm{s}, \mathrm{ult}}+\mathrm{Q}_{\mathrm{b} \text {,ult }}
$$

olarak ifade edilebilir. Burada;

Qult : Nihai kazık taşıma kapasitesi,

$\mathrm{Q}_{\mathrm{s}, \mathrm{ult}} \quad$ : Nihai kazık çevre taşıma kapasitesi,

Qb,ult : Nihai kazık uç taşıma kapasitesidir. 
Kazık taşıma gücünü belirlemek için Meyerhof [4], SPT verilerine dayalı olarak iri daneli zeminlerde öneride bulunmuştur. Çakma ve delme (fore) imalat tipine göre farklılık gösteren bu ampirik katsayılar ile SPT verileri ile kazık taşıma gücü belirlenebilmektedir.

Bazaara ve Kurkur [5] ise 1986 yılında Mısır zeminlerinde imal edilen delme (fore) kazıklar için belirli arlıklarda ampirik katsayılar aracılığı ile SPT verilerine dayalı bağıntılar önermişlerdir.

Decourt [6] tarafindan yapılan çalışmada çakma ve delme (fore) kazıklar için ince daneli veya iri daneli zeminlerde bulunma durumlarına göre, SPT değerlerine bağlı olarak ampirik katsayılar önerilmiştir.

$\mathrm{Bu}$ çalışmada teorik ve ampirik olarak önerilen kazık taşıma gücü bağıntılarının tam ölçekli kazık yükleme deneyi değerlendirme yöntemleri ile karşılaştırılarak bu iki hesap bloğu arasındaki uyumun ya da uyumsuzluğun ortaya konulması amaçlanmıştır.

\section{Materyal ve Yöntem}

\subsection{Materyal}

Araştırmada, Türkiye'nin çeşitli illerinde yapılan sekiz adet kazık yükleme deneyinin verileri kullanılmıştır. Bu veriler, imalatın müşavirliğini yürüten firmalardan alınmıştır.

Tablo 2.1. Araştırma kapsamında kullanılan kazık yükleme deneylerine ait genel bilgiler

\begin{tabular}{|c|c|c|c|c|c|c|c|}
\hline \multirow{2}{*}{$\begin{array}{c}\text { Veri / } \\
\text { Deney No }\end{array}$} & \multirow{2}{*}{$\begin{array}{c}\text { İmalat } \\
\text { Tipi }\end{array}$} & \multirow{2}{*}{$\begin{array}{l}\text { Çalışma } \\
\text { Biçimi }\end{array}$} & \multicolumn{2}{|c|}{ Kesit Geometrisi } & \multirow{2}{*}{$\begin{array}{l}\text { Uzunluk } \\
\text { (m) }\end{array}$} & \multirow{2}{*}{ Çevre Zemini } & \multirow{2}{*}{$\begin{array}{c}\text { Uç } \\
\text { Zemini }\end{array}$} \\
\hline & & & Şekli & Çap / Ayrıt (m) & & & \\
\hline 1 & Fore & Basma & Daire & 1,20 & 36,00 & Ayrışmış Kaya / Kil & Kil \\
\hline 2 & Fore & Basma & Daire & 1,00 & 25,00 & Ayrışmış Kaya / Kil & Kil \\
\hline 3 & Fore & Çekme & Daire & 0,80 & 18,00 & Ayrışmış Kaya / Kil & Kil \\
\hline 4 & Fore & Basma & Daire & 1,00 & 20,00 & Ayrışmış Kaya / Kil & Kil \\
\hline 5 & Fore & Basma & Daire & 1,00 & 34,00 & Ayrışmış Kaya / Kil & Kil \\
\hline 6 & Fore & Basma & Daire & 0,80 & 26,00 & Çakıl / Kum & Kil \\
\hline 7 & Fore & Basma & Daire & 0,65 & 25,00 & Kil & Kil \\
\hline 8 & Çakma & Çekme & Daire & 0,65 & 30,30 & Kil & Kil \\
\hline
\end{tabular}

\subsection{Yöntem}

Bu çalışma kapsamında, deney kazıklarının içerisinde bulunduğu zemin tipi ve imalat şekline uygun olan SPT'ye dayalı kazık taşıma gücü belirleme yöntemleri ile matematik modele dayalı kazık yükleme deneyi değerlendirme yöntemleri kıyaslanmıştır. İlgili yöntemler ilerleyen bölümlerde detaylı olarak anlatılmıştır. 


\subsubsection{Standart Penetrasyon Deneyinden Kazık Taşıma Gücünün Bulunması}

Türkiye'de ve Dünya'da oldukça yaygın olarak kullanılmış olan ve kullanımına devam edilen Standart Penetrasyon Deneyi, zemin sıkılığını/kıvamını belirleyen bir deney olmasıyla kazık taşıma gücü hesabına da yardımcı olmaktadır. Bu çalışmada önerisi kullanılan bazı araştırmacıların konuyla ilgili ampirik bağıntı önerileri Tablo 2.2'de verilmiştir.

Tablo 2.2. SPT deneyine dayalı kazık taşıma gücü belirleme yöntemleri

\begin{tabular}{|c|c|c|}
\hline Araştırmacı & $\begin{array}{l}\text { Uç Direnci }\left(\mathrm{q}_{\mathrm{b}}\right) \text { ve } \\
\text { Çevre Direnci }\left(\mathrm{q}_{\mathrm{s}}\right)\end{array}$ & Açıklamalar \\
\hline \multirow{5}{*}{ Meyerhof [4] } & $m \cdot N_{b} \leq\left(\frac{L}{D}\right)$ & $\begin{array}{l}\mathrm{N}_{\mathrm{b}} \text { : Kazık tabanından 10D kadar üstteki ve 5D } \\
\text { kadar alttaki SPT vuruş değerlerinin ortalaması }\end{array}$ \\
\hline & \multirow[t]{2}{*}{ şartı ile; } & $\begin{array}{l}\mathrm{N}_{\mathrm{s}} \text { : Hesap edilecek ilgili katman boyunca yapılan } \\
\mathrm{SPT} \text { vuruş değerlerinin ortalaması }\end{array}$ \\
\hline & & Delme (fore) kazıklar: $\mathrm{n}_{\mathrm{s}}=1, \mathrm{k}=0,012, \mathrm{~m}=0,12$ \\
\hline & $\mathrm{q}_{\mathrm{b}}(\mathrm{MPa})=\mathrm{k} \cdot \mathrm{N}_{\mathrm{b}}$ & Çakma kazıklar: $n_{s}=2, k=0,04, m=0,4$ \\
\hline & $\mathrm{q}_{\mathrm{s}}(\mathrm{kPa})=\mathrm{n}_{\mathrm{s}} \cdot \mathrm{N}_{\mathrm{s}}$ & Sadece iri daneli zeminler için geçerlidir. \\
\hline \multirow{4}{*}{$\begin{array}{l}\text { Bazaara ve } \\
\text { Kurkur [5] }\end{array}$} & $\mathrm{q}_{\mathrm{b}}(\mathrm{MPa})=\mathrm{n}_{\mathrm{b}} \cdot \mathrm{N}_{\mathrm{b}}$ & $\begin{array}{l}\mathrm{N}_{\mathrm{b}}: \mathrm{N}_{\mathrm{b}} \leq 50 \text { şartı ile kazık tabanından } 1 \mathrm{D} \text { kadar } \\
\text { üstteki ve } 3,75 \mathrm{D} \text { kadar alttaki SPT-N değerlerinin } \\
\text { ortalaması }\end{array}$ \\
\hline & \multirow{3}{*}{$\mathrm{q}_{\mathrm{s}}(\mathrm{kPa})=\mathrm{n}_{\mathrm{s}} \cdot \mathrm{N}_{\mathrm{s}}$} & $\begin{array}{l}\mathrm{N}_{\mathrm{s}} \text { : Hesap edilecek ilgili katman boyunca yapılan } \\
\text { SPT vuruş değerlerinin ortalaması }\end{array}$ \\
\hline & & nb: $0,06 \sim 0.2 \quad$ ns: $2 \sim 4$ \\
\hline & & Delme (fore) kazıklar için geçerlidir. \\
\hline \multirow{7}{*}{ Decourt [6] } & \multirow{7}{*}{$\mathrm{q}_{\mathrm{s}}(\mathrm{kPa})=\alpha \cdot\left(2,8 \cdot\left(\mathrm{N}_{\mathrm{s}}\right)_{60}+10\right)$} & İnce daneli zeminlerde: $\alpha=1.0$ \\
\hline & & İri daneli zeminlerde: $\alpha=0,5-0,6$ \\
\hline & & İri daneli zeminlerde: $\mathrm{k}_{\mathrm{b}}=0,325$ \\
\hline & & İnce daneli zeminlerde çakma kazık: $\mathrm{k}_{\mathrm{b}}=0,10$ \\
\hline & & İnce daneli zeminlerde fore kazık: $\mathrm{k}_{\mathrm{b}}=0,08$ \\
\hline & & $\begin{array}{l}\left(\mathrm{N}_{\mathrm{b}}\right)_{60}: \text { Kazık tabanı çevresindeki düzeltilmiş SPT } \\
\text { vuruş değerlerinin ortalaması }\end{array}$ \\
\hline & & $\begin{array}{l}\left(\mathrm{N}_{\mathrm{s}}\right)_{60} \text { : Hesap edilecek ilgili katman boyunca } \\
\text { yapılan düzeltilmiş SPT vuruş değerlerinin } \\
\text { ortalaması }\end{array}$ \\
\hline
\end{tabular}

$\mathrm{Bu}$ çalışmanın ağırlıklı olarak ince daneli zeminlerde imal edilen kazıklardan oluşması nedeniyle sadece Tablo 2.1.'de verilen ampirik yöntemler kullanılmıştır.

\subsubsection{Standart Penetrasyon Deneyi İle İlgili Düzeltmeler}

İri daneli zeminlerde kayma direncinin normal gerilmeye bağlı olması nedeniyle derinlere indikçe artan SPT değerinde örtü yükü düzeltmesi yapılmıştır. Önalp ve Sert [3] literatürdeki düzeltmelerin en güvenilir olanı olarak Denk. (2.1)'i önermişlerdir. 


$$
\mathrm{C}_{\mathrm{N}}=\sqrt{\frac{95,76}{\sigma_{0}^{\prime}}}
$$

Literatürdeki SPT deneyine bağlı birçok korelasyonun \%60 enerji oranına göre belirlenmesi nedeniyle bu düzeltme ise Denk. (2.2) ile gerçekleştirilmiştir [3].

$$
\mathrm{N}_{60}=\frac{\mathrm{E}_{\mathrm{r}} \cdot \mathrm{C}_{\mathrm{B}} \cdot \mathrm{C}_{\mathrm{S}} \cdot \mathrm{C}_{\mathrm{R}}}{60} \cdot \mathrm{N}_{\mathrm{a}}
$$

İnce daneli zeminlerde, pratikte, örtü yükü düzeltmesi yapılmamaktadır [3]. Enerji verim düzeltmesi dahil olmak üzere diğer düzeltmeler ise Türkiye'de yaptıkları araştırma sonucu Sivrikaya ve Toğrol [13] tarafından önerilen Denk. (2.3) kullanılmıştır.

$$
\mathrm{N}_{60}=0,75 \cdot \mathrm{C}_{\mathrm{R}} \cdot \mathrm{N}_{\mathrm{a}}
$$

\subsubsection{SPT Yapılamayan Ayrışmış Kaya Birimlerde Taşıma Gücü}

Yapılan deneylerde bazı kazıkların çevre bölgesinin bir kısmı ayrışmış kaya birimler içerisindedir. Ayrı̧̧ıı̧ kaya birimlerde laboratuvar deneylerinden taşıma ücü kapasitesi belirlemek oldukça zordur. Ayrışmış kaya birimleri kaya kabul etmek aşırı taşıma gücü değerleri, zemin kabul etmek ise muhafazakar taşıma gücü değerleri verebilir. Bu nedenle bu çalışmada, ayrışmış kaya birimlerin sürtünme direnci Broms ve ark. [14] önerisi ile $120 \mathrm{kPa}$ olarak değerlendirmeye alınmıştır.

\subsection{Kazık Yükleme Deneyi}

\subsubsection{Eksenel Kazık Yükleme ve Çekme Deneyi}

Kazıkların içinde bulundukları zeminin deterministik olarak ideal biçimde olmaması nedeniyle kazığın teorik yaklaşımlarla taşıma kapasitesini belirlemek her zaman gerçeği yansıtmayabilir. $\mathrm{Bu}$ nedenle kazık taşıma gücünü daha isabetli belirlemek amacıyla kazık yükleme deneylerine başvurulur.

Statik kazık yükleme deneyleri kazığın üzerine ölü yük uygulayarak veya deney kazığının çevresine gereken reaksiyon sistemi yapılarak bir düzenek yardımıyla gerçekleştirilebilir. Kazık üzerine uygulanan yükler belirli zaman aralıklarında artırılarak ya da artırlıp azaltılarak (çevrimsel) yük oturma ilişkisi irdelenerek deney yorumlanır. Statik kazık yükleme deneyi ile ilgili Dünya'da en yaygın kullanılan şartnameler; basma deneyinde ASTM D1143 [7], çekme deneyinde ASTM D3689 [8] olmuştur.

Kazık yükleme deneyinden elde edilen yük-oturma eğrisi üzerine ilk bakışta kazığın göçmeye ulaşıp ulaşmadığı hakkında bir yorum yapılabilir. Örneğin; Şekil 2.1 incelendiğinde kazık yükleme deneylerine ait tipik yük-oturma eğrileri $\mathrm{A}, \mathrm{B}$ ve $\mathrm{C}$ adında ve aynı grafik üzerinde gösterilmektedir. Buradan A ve B'nin doğrusal olmayan hatta geçtiğini ve dolayısıyla göçme yüküne ulaştı̆̆ anlaşılabilir. Ancak kazık yükleme deneylerinin sonucunda çoğunlukla $\mathrm{C}$ gibi bir yük-oturma eğrisi ile karşılaşı1ır. C gibi bir yük-oturma eğrisine sahip kazık yükleme deneylerinin kazık göçme yükünün 
belirlenmesi ancak yorumla mümkündür. Bu nedenle kazık yükleme deneylerinin yorumlanması büyük önem taşımaktadır [9].

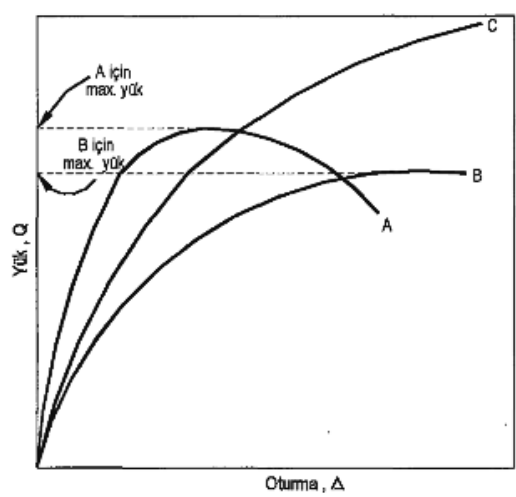

Şekil 2.1. Kazık yükleme deneylrine ait başlıca tipik yük - oturma eğrileri [9]

\subsubsection{Matematik Modele Dayalı Kazık Yükleme Deneyi Değerlendirme Yöntemleri}

Kazık yükleme deneylerinin matematiksel olarak değerlendirilmesi, yük-oturma eğrisi üzerinde yapılan işlemler sonucunda bu eğriyi matematik bir model haline getirip bu model üzerinden ekstrapolasyon ile göçme yüküne ulaşılmasıdır.

\subsubsection{Chin-Kondner Yöntemi}

Chin [10], Kondner'in 1963 'te gerilme - deformasyon üzerine yaptığı çalışmayı tüm kazıklar için genelleyerek, göçme yüküne ulaşmamış kazık yükleme deneylerinin ekstrapolasyon ile yorumlanması üzerine bir yöntem geliştirmiştir. Bu yöntemde Şekil 2.2.'deki gibi oturma/yük oturma dağılımı çizilir. Doğrusal dağılım gösteren noktalar ideal bir doğru üzerinde birleştirilir. Bu doğrunun (oturma/yük) eksenini kestiği nokta $C_{2}$, doğrunun eğimine ise $C_{1}$ ise; doğrunun eğiminin tersi, kazığın göçme yükünü vermektedir.

$$
\mathrm{Q}_{\text {ult }}=\frac{1}{\mathrm{C}_{1}}
$$

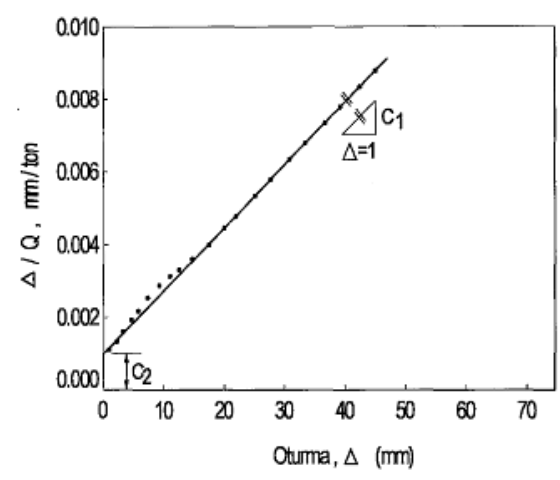

Şekil 2.2. Chin-Kondner yöntemi [9]

$$
\mathrm{Q}=\frac{\Delta}{\mathrm{C}_{1} \cdot \Delta+\mathrm{C}_{2}}
$$

bağıntısından elde edilir. 
Chin-Kondner Yöntemi, deneyin herhangi bir safhasında yapılabilir. Fakat oturma/yük-oturma grafiğinin doğrusal bir dağılıma ulaşabilmesi için deneyin henüz başında sayılabilecek oturma değerlerinde yapılması tavsiye edilmemektedir.

\subsubsection{Decourt (1999) Yöntemi}

$\mathrm{Bu}$ yöntemde her kademedeki yük değeri kendisine karşılık gelen oturma değerine bölünür ve elde edilen değerler ile yük değerleri bir grafik üzerinde dağılım halinde gösterilir [11].

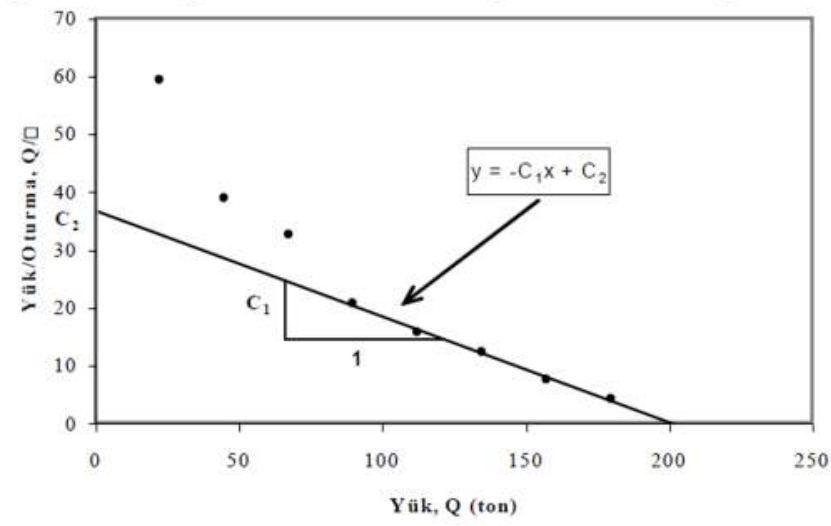

Şekil 2.3. Decourt yöntemi [9]

Dağılımın lineer olan nokta serileri yaklaşık bir doğru üzerinde birleştirilir. Bu yaklaşık doğrunun eğimi $\mathrm{C}_{1}$, yük/oturma eksenini kestiği noktanın niceliğine $\mathrm{C}_{2}$ ise, göçme yükü:

$$
\mathrm{Q}_{\mathrm{ult}}=\frac{\mathrm{C}_{2}}{\mathrm{C}_{1}}
$$

şeklinde ifade edilir. İdeal eğrinin denklemi ise:

$$
\mathrm{Q}=\frac{\mathrm{C}_{2} \cdot \Delta}{1-\mathrm{C}_{1} \cdot \Delta}
$$

şeklinde ifade edilir.

Decourt yöntemi ile Chin-Kondner yönteminin sonuçları birbirine oldukça yakındır. Deneyin herhangi bir safhasında yapılabilir. Fakat başlangıçta az nokta elde edilebilmesi nedeniyle deneyin yanlış yorumlanma ihtimali olabileceğinden dağılımın doğrusal seriye ulaşması beklenmelidir.

\subsubsection{3. Özkan-Alku Yöntemi}

Alku [37] tarafından göçme yüküne kadar yüklenmeyen kazıkların değerlendirilmesi ve mevcut şartlarda en iyi şekilde yorumlanabilmesi amacıyla 40 adet kazık yükleme deneyi üzerinden geliştirilmiştir. 
$\mathrm{Bu}$ yöntemde esas olan yük-oturma grafiğini tek fonksiyon olarak değil çift fonksiyon olarak belirlemektir. Göçme (nihai) yükünün bulunması ise başlangıç değil, son fonksiyon aracığılıyla yapilmaktadır [12].

Son fonksiyon için Şekil 3.9‘daki gibi $\sqrt{ } \mathrm{Q} / \delta$ - Q (yükün karekökü bölü oturma - yük) grafiği çizilir. $\mathrm{Bu}$ dağglımdaki noktalar belli bir değerden sonra doğrusal halde ilerler. Bu noktalar birleştirilerek oluşturulan doğrunun eğimi ve düşey ekseni kestiği nokta bulunur. Apsisi kesen nokta Özkan-Alku göçme yükünü vermektedir.

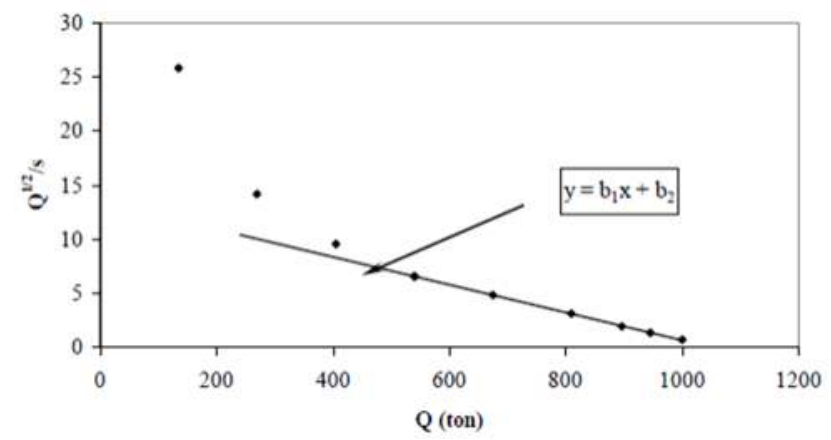

Şekil 2.4. Özkan-Alku yöntemi [10]

\section{Araştırma Bulguları}

Yapılan çalışmaların sonuçları zemin tiplerine göre, her zemin tipi için ortalama değerler üzerinden verilmiştir. Sekiz deney kazığının ilk yedi tanesi ayrışmış kaya ve ince daneli zeminler içerisinde; bir tanesi (6 no.'lu deney kazığı) ise kazık çevresi iri daneli, kazık ucu ise ince daneli zemin içerisindedir.

Şekil 3.1, Şekil 3.2, Şekil 3.3 ve Şekil 3.4'te sırasıyla verilmiş olan 1, 2, 3 ve 4 no.'lu deney kazıklarında en yüksek göçme yükünü Chin-Kondner (1970) ve Decourt (1999) yöntemleri vermiştir. Decourt (1996), Bazaraa ve Kurkur (1986), Özkan-Alku (2006) yöntemleri ise birbirlerine yakın ve kazık yükleme değerlerinden daha düşük göçme yükü vermişlerdir.

Şekil 3.5'te sonuçları verilmiş olan 5 no.'lu deney kazığında en yüksek göçme yükünü Chin-Kondner (1970) yöntemi vermiş olup, bunu sırasıyla Decourt (1995) yöntemi, Decourt (1999) yöntemi, Bazaara ve Kurkur (1986) yöntemi ve Özkan-Alku (2006) yöntemi takip etmiştir.

Şekil 3.6'da sonuçları verilen 6 no.'lu deney kazığında en yüksek göçme yükünü Meyerhof (1986) yöntemi vermiş olup, bunu sırasıyla Chin-Kondner (1970) yöntemi, aynı göçme yüklerini veren Decourt (1996) ve Decourt (1999) yöntemleri ve Özkan-Alku (2006) yöntemi takip etmiştir.

Şekil 3.7'de verilen 7 no.'lu deney kazığında ise matematiksel modele dayalı yöntemler birbirine yakın ve ampirik yöntemlerden fazla göçme yükü vermişlerdir. En yüksek göçme yükünü ChinKondner (1970) yöntemi vermiş olup bunu sırasıyla Decourt (1999) yöntemi, Özkan-Alku (2006) yöntemi, Decourt (1995) yöntemi ve Bazaraa ve Kurkur (1986) takip etmiştir.

Şekil 3.8'de verilmiş olan 8 no.'lu deney kazıdığında en yüksek göçme yükünü Decourt (1995) yöntemi vermiştir. Bu yöntemin ardından gelen göçme yükü değerleri, büyüklük olarak, sırasıyla Chin-Kondner (1970) yöntemi, Decourt (1999) yöntemi ve Özkan-Alku (2006) yöntemi’nin verdiği göçme yükü değerleridir. 


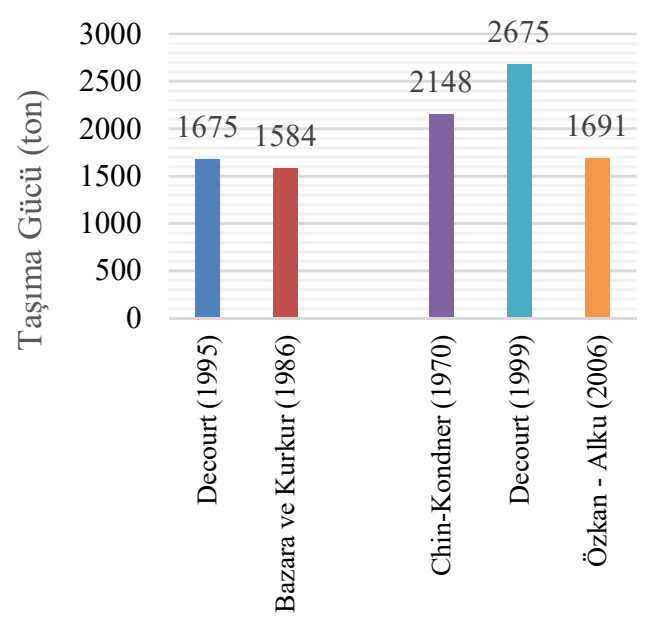

Şekil 3.1. 1 no.'lu deney kazığı analiz sonuçları

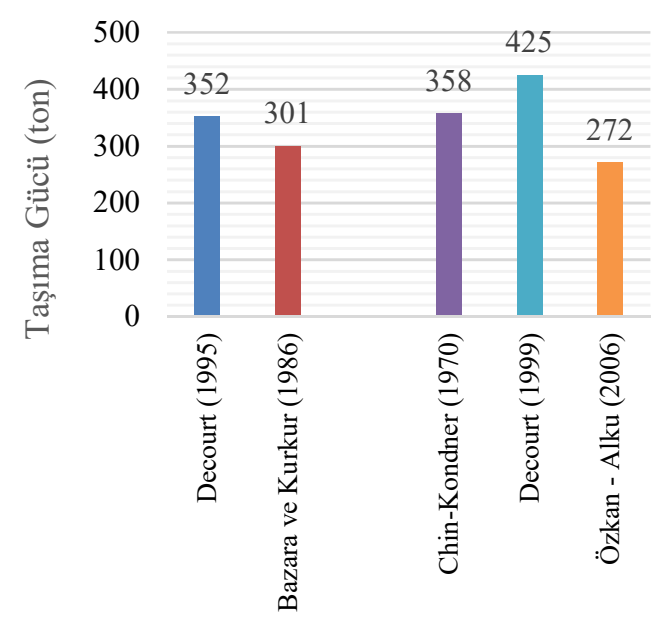

Şekil 3.3. 3 no.'lu deney kazığı analiz sonuçları

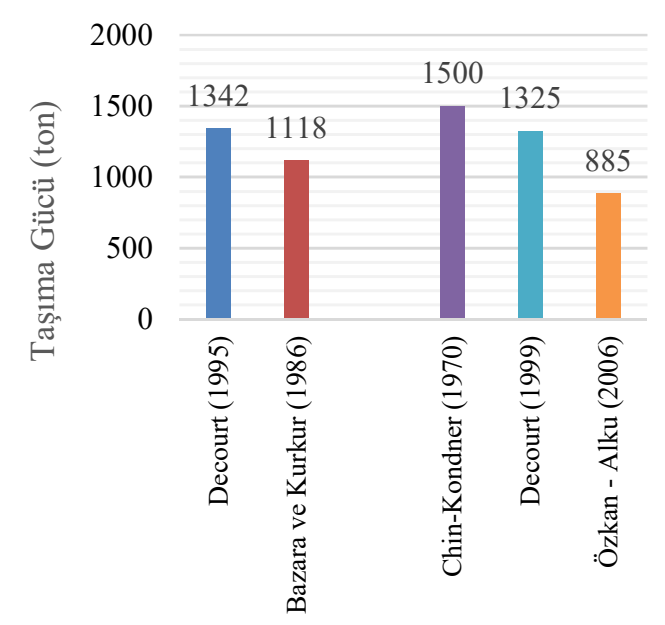

Şekil 3.5. 5 no.'lu deney kazığı analiz sonuçları

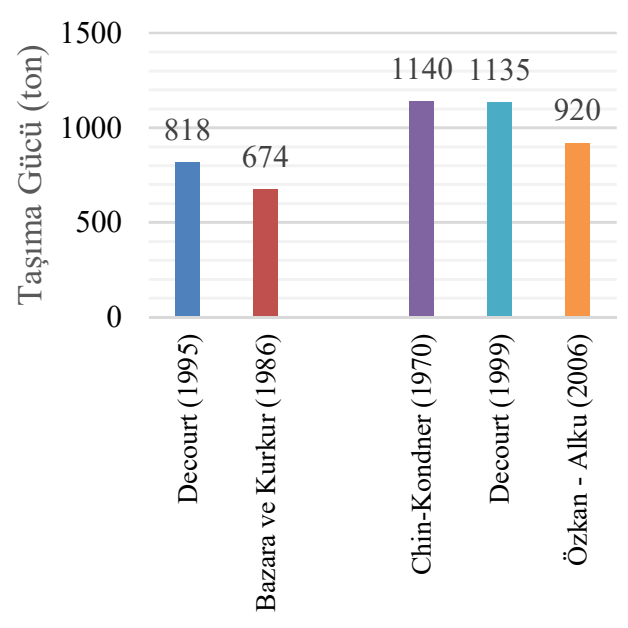

Şekil 3.2. 2 no.'lu deney kazığı analiz sonuçları

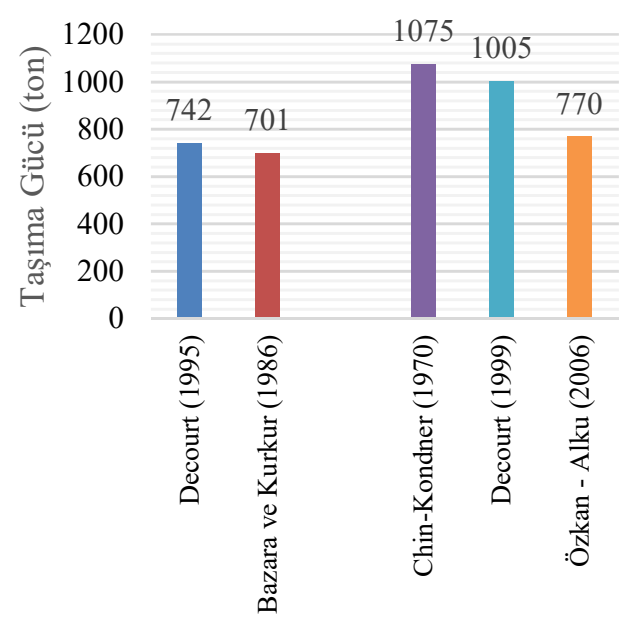

Şekil 3.4. 4 no.'lu deney kazığı analiz sonuçları

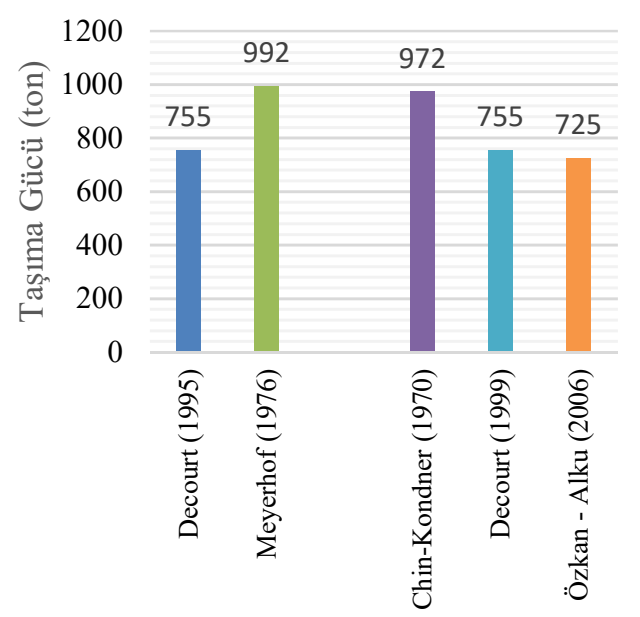

Şekil 3.6. 6 no.'lu deney kazığı analiz sonuçları 


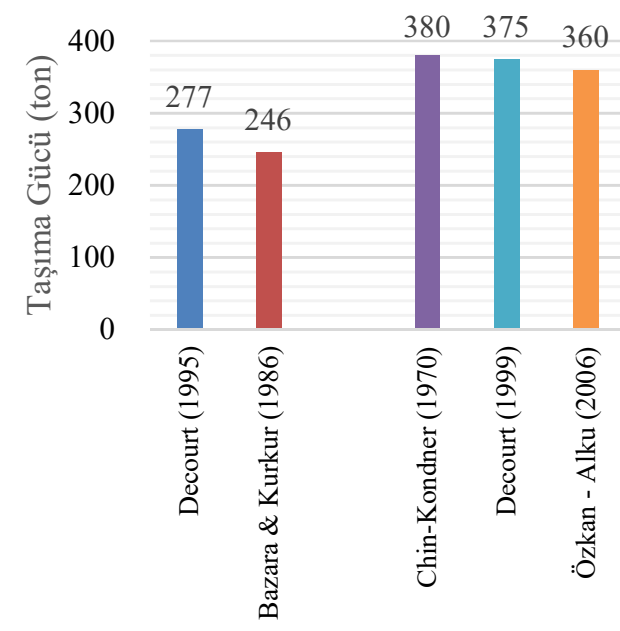

Şekil 3.7. 7 no.'lu deney kazığı analiz sonuçları

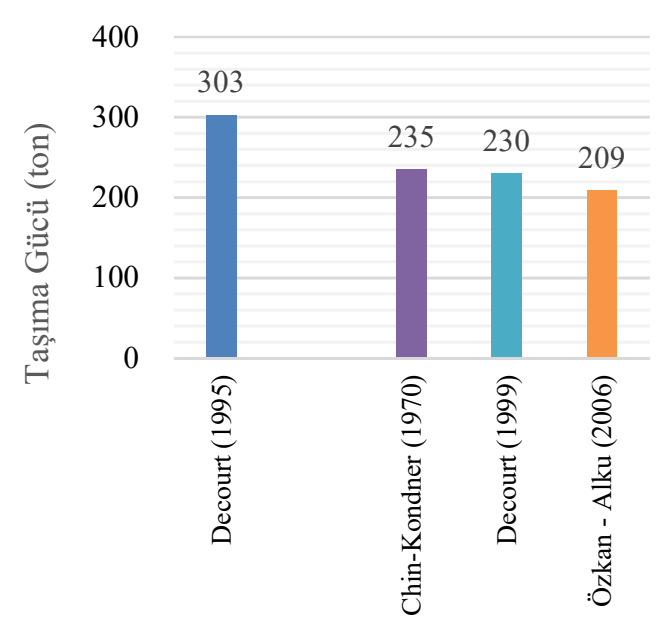

Şekil 3.8. 8 no.'lu deney kazığı analiz sonuçları

Zemin tiplerine göre değerlendrme yapabilmek için çevresi ayrışmış kaya ve ince daneli zeminler içerisinde olan, ucu ise sadece ince daneli zeminler içerisinde olan ilk yedi deney kazığı, iri daneli zeminler içerisinde bulunan 6 no.'lu deney kazığından bağımsız olarak irdelenmiştir.

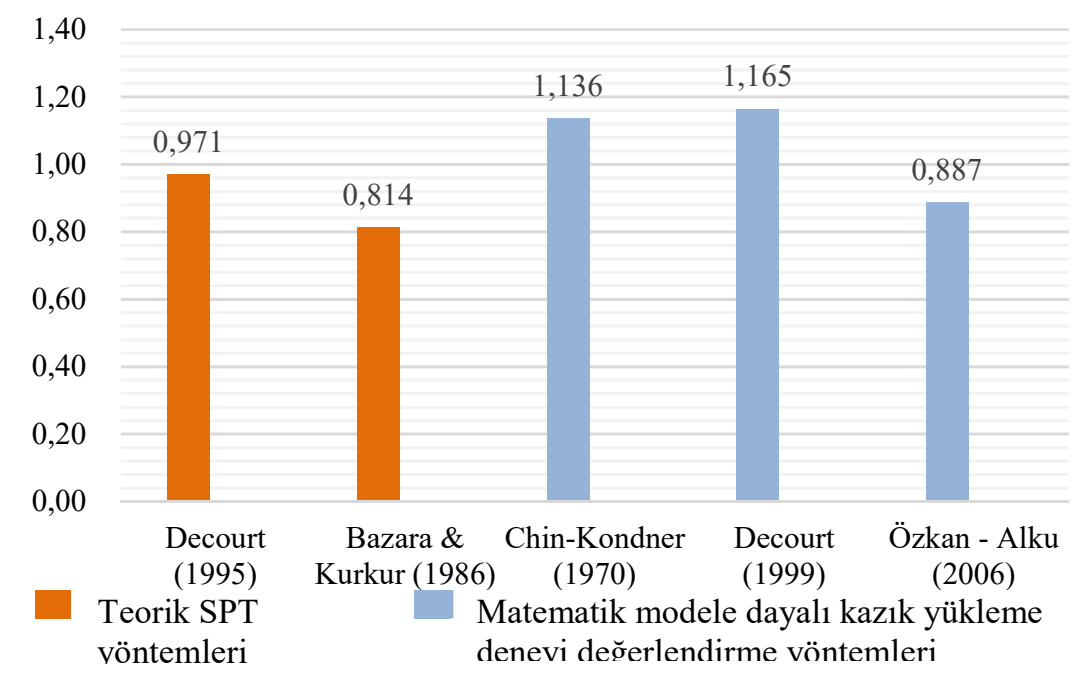

Şekil 3.9. Çevresi ayrışmış kaya ve ince daneli zeminde, ucu ince daneli zeminde olan deney kazıklarında her bir yöntem için hesap edilen değerlerin, bu değerlerin ortalamasına olan oranlarının ortalaması

Şekil 3.9.'a göre, çevresi ayrışmış kaya ve ince daneli zeminde, ucu ince daneli zeminde olan deney kazıklarında teorik SPT yöntemleri ve matematik modele dayalı kazık yükleme deneyi değerlendirme yöntemleri iki ayrı blok olarak kıyaslanmıştır. Bu kıyaslamada birbirine en yakın sonuçları veren iki yöntem yaklaşık \%9'luk bir farkla Bazaraa \& Kurkur (1986) ve Özkan-Alku (2006) yöntemleri olduğu görülmüştür. Tüm yöntemlerin ortalamalarına en uzak değeri ise, teorik yöntemlerden, ortalamaların 0.814 katı değeri veren Bazaara ve Kurkur (1986) yöntemi; kazık yükleme deneyi değerlendirme yöntemlerinden ise ortalamaların 1.165 katı değer veren Decourt (1999) yöntemi olmuştur. 
Çevresi iri daneli zeminde, ucu ise ince daneli zeminde olan 6 no.'lu deney kazığında Decourt (1995) ve Decourt (1999) yöntemlerinin tamamen aynı sonuçları verdiği görülmüştür. Burada teorik Meyerhof (1976) yöntemi ortalamanın yaklaşık \%24 üzerinde bir göçme değeri vermiştir. Özkan-Alku (2006) yöntemi ise ortalamadan \%14 daha düşük bir göçme yükü sunmuştur.

\section{Sonuçlar}

Bu çalışmada 8 adet kazık yükleme deneyi kazıkları üzerinde iki araştırmacının sunduğu SPT verilerne dayalı teorik yöntem ve üç araştırmacının önerdiği matematik modele dayalı kazık yükleme deneyi değerlendirme yöntemlerine göre göçme yükü (nihai taşıma gücü) tahlilleri yapılmıştır.

İnce daneli zeminlerdeki deney kazıklarında SPT verilerinden taşıma gücü veren yöntemler kendi aralarında incelendiğinde Decourt (1995) yönteminin Bazaara ve Kurkur (1986) yönteminden \%13.8 daha fazla göçme yükü değeri verdiği tespit edilmiştir. Bu deneylerde uygulanan kazık yükleme deneyi değerlendirme yöntemleri içerisinde ise en fazla yükü Decourt (1999) yöntemi vermiş olup tüm yöntemlerin ortalamasının \%16.5 üzerindedir. Chin-Kondner (1970) yöntemi ise tüm yöntemlerin ortalamasından \%13.6 fazla, Özkan-Alku (2006) yöntemi ise tüm yöntemlerin ortalamasından \%11.3 daha az göçme yükü vermiştir. Ampirik yöntemler ve kazık yükleme deneyi değerlendirme yöntemlerini iki ayrı hesap bloğu olarak kıyasladığımızda ise birbirine en yakın yöntemler Bazaraa ve Kurkur (1986) yöntemi ile Özkan-Alku (2006) yömtemleri olmuştur. ÖzkanAlku (2006) yöntemi Bazaraa ve Kurkur (1986) yönteminden \%9.7 daha fazla göçme yükü vermiştir.

6 numaralı deney kazığı ise çevresi iri daneli, ucu ince daneli zeminleri içerisinde olan bir kazıktır. $\mathrm{Bu}$ nedenle müstakil olarak değerlendirilmiştir. Ampirik yöntemler içerisinde değerlendirme yapıldığında Meyerhof (1976) yönteminin Decourt (1995) yönteminden \%31.4 daha fazla göçme yükü verdiği görülmüsstür. Kazık yükleme deneyi değerlendirme yöntemleri içerisinde ise en yüksek göçme yükünü Decourt (1999) yöntemi vermiş olup Chin-Kondner (1970) yönteminden \%28.7 daha fazla, Özkan-Alku (2006) yönteminden ise \%34.1 daha fazla göçme yükü vermiştir. Ampirik yöntemler ve kazık yükleme deneyi değerlendirme yöntemlerini iki ayrı hesap bloğu olarak kıyasladı̆̆ımızda ise birbirine en yakın yöntemler Decourt (1995) yöntemi ve Decourt (1999) yöntemleri olup tamamen aynı sonucu vermişlerdir.

Yapılan çalışmalardan elde edilen araştırma bulguları neticesinde;

İnce daneli zeminler içerisinde bulunan kazıklarda birbiriyle ve ortalama ile en uyumlu yöntemlerin Bazaraa ve Kurkur (1986) ampirik yöntemi ile Özkan-Alku (2006) kazık yükleme deneyi değerlendirme yönteminin olduğu, İri daneli zeminler içerisinde bulunan fore kazıklarda birbiriyle ve ortalama ile en uyumlu yöntemlerin Decourt (1995) ampirik yöntemi ile Decourt (1999) kazık yükleme deneyi değerlendirme yönteminin olduğu,

Tüm yöntemlerin ortalamasını ne derecede etkileyeği, bu yöntemler spektrumunda nerede duracağının tespit edilmesi ve bu yöntemlerin değerlendirilmesine etki edip etmeyeceğini belirlemek amacıyla sonlu eleman yöntemi de bu yöntemlerle birlikte incelenebilir. 


\section{Kaynaklar}

[1] Kabaca, H., Kazık Taşıma Gücü ve Oturma Analiz Yöntemleri, Kazik Yükleme Deneyleri ve Plaxis 2D Analizleri İle Karşılaştırılarak Kazıklarin Taşıma Gücüne Yönelik Yeni Bir Yaklaşım Metodu, Yüksek Lisans Tezi, Sakarya Üniversitesi, 2018.

[2] Uzuner, B.A., "Temel Mühendisliğine Giriş”, Derya Kitabevi, 187-219, Trabzon, 2006.

[3] Önalp, A., Sert, S., “Geoteknik Bilgisi III Bina Temelleri”, Birsen Yayınevi, 277-342, İstanbul, 2010.

[4] Meyerhof, G.G., "Bearing Capacity and Settlement of Pile Foundations", Journal of Geotech. Eng. Div., ASCE, Vol.102, No.GT3, 1976.

[5] Bazaraa AR \& Kurkur MM, "N-values used to predict settlements of piles in Egypt", Proceedings of In Situ '86, New York, 1986, sf. 462-474.

[6] Decourt L, "Prediction of load-settlement relationships for foundations on the basis of the SPT" Ciclo de Conferencias Internationale, Leonardo Zeevaert, UNAM, Mexico, 1995, pp. 85-104.

[7] ASTM D 1143-81., 1989. "Standart Test Method For Piles Under Statical Axial Compressive Loads”, American Society for Testing and Materials, Philedelphia.

[8] ASTM D 3689., 1989. "The Standart Method Of Testing Individual Piles Under Statical Axial Tensile Loads”, American Society for Testing and Materials, Philedelphia.

[9] Düzceer, İ.R., "Kazık Yükleme Deneyleriyle Nihai Kazık Taşıma Kapasitesinin Belirlenmesi Üzerine Bir Çalışma”, Doktora Tezi, İstanbul Teknik Üniversitesi, 2002.

[10] Chin, F.K. "Estimation of the Ultimate Load of Piles Not Carried to Failure", Proc. 2nd Southeast Asia. Conference on soil Engineering, sf. 81-90, 1970.

[11] Decourt, L., 1999. "Behaviour of Foundations Under Working Load Conditions", Proc. of the 11th Pan-American Conf. on Soil Mechanics and Geotechnical Engineering, Dolguassu, Brasil, V. 4, sf. 453-488.

[12] Alku, Y., Kazık Yükleme Deneylerinin Değerlendirilmesi İle İlgili Bir İnceleme, Yüksek Lisans Tezi, İstanbul Teknik Üniversitesi, Şubat 2006.

[13] Sivrikaya, O., Toğrol, E., İnce daneli zeminlerde SPT sonuçlarının düzeltilmesi üzerine bir çalışma, itüdergisi/d mühendislik, Cilt: 2, Sayı: 6, 59-67, Aralık 2003.

[14] Broms, B., Chang, M.F., Goh, A.T.C., "Bored Piles in Residual Spil and Weathered Rocks in Singapore", Deep Foundations on Bored and Auger Piles, Balkema, 1988, pp. 17-34. 